\title{
Effect of Additive Concentration during Copper Deposition using EnFACE Electrolyte
}

\author{
E. M. Dela Pena ${ }^{1,3,4}$, N. Bains ${ }^{2}$, A. Hussain ${ }^{2}$, A. Cobley ${ }^{2}$ (FIMF), S. Roy (FIMF) $)^{1,3}$
}

${ }^{1}$ Chemical and Process Engineering, Strathclyde University, James Weir Building, Glasgow, G1 IXJ

\footnotetext{
${ }^{2}$ Functional Materials Group, Coventry University, Priory Street, Coventry, CV1 5FB

${ }^{3}$ School of Chemical Engineering and Advanced Materials, Newcastle University, Merz Court, Newcastle NE1 7RU*
}

${ }^{4}$ Department of Mining, Metallurgical and Materials Engineering, University of the Philippines, Diliman, Quezon City, 1101, Phillipines

\section{Abstract}

Copper deposition from solutions using high concentration of acid, metal ions and polyethylene glycol (PEG), and bis-(3-sulfopropyl) disulfide (SPS) and chloride ions ( $\mathrm{Cl}^{-}$) is well known. A recent maskless micropatterning technology, which has the potential to replace traditional photolithographic process, called EnFACE, proposed using an acid-free, low metal ion solution which is in direct contrast to those used in standard plating technology. In this work copper has been deposited using standard electroplating solutions and those used in the EnFACE process. In the standard electrolyte $0.63 \mathrm{M} \mathrm{CuSO}_{4}$ and $2.04 \mathrm{M}$ $\mathrm{H}_{2} \mathrm{SO}_{4}$ has been used, along with Gleam additives supplied by Dow Chemicals. For the Enface electrolyte, copper deposition has been carried out using without any acid, and with different concentrations of additives between $17 \%-200 \%$ of those recommended by suppliers. 25 um of metal has been plated on stainless steel coupons as suggested by and ASTM, peeled off and subjected to ductility and resistance measurements. Scanning electron microscopy and electron back scatter diffraction has been carried out to determine the deposit morphology. It was found that copper deposits obtained from acid-free solutions containing low concentration of metal ion and additives produced copper deposits had properties which are comparable to those obtained from standard electrolytes. The optimum additive concentration for the EnFACE electrolyte was $50 \%$ of the recommended value. 
Keywords: EnFACE process, copper film, additives, electrodeposition, electroplating.

\subsection{Introduction}

Copper is the standard metal used in wiring printed circuit boards [1] and interconnects in electronic devices [2]. The standard manufacturing process for both these technologies uses electrodeposition. It is well established that the electrodeposition processes employ electrolyte chemistry of high metal and acid concentrations and employ additives, which impart desirable properties to the plated copper [3]. Numerous studies geared on understanding the role of additives in electroplating have concluded that these chemicals are essential to obtaining metal deposits of high quality [4-9].

Recently a new mask-less process, called EnFACE, has been proposed to deposit microscale copper features [10]. As opposed to the standard electrolytes used for PCB and electronic manufacturing, EnFACE proposed a solution using $0.1 \mathrm{M} \mathrm{CuSO}_{4}$ and no acid [1015]. Since most of the current literature is has been focused on in understanding the role of additives in the established processes [16-19], the effect on this new chemistry on deposited copper is still unknown. In addition, it is unclear how much additive is required to change deposit properties and what effect they would have on the deposit.

This work examines the effect of additives on deposit properties when copper is deposited from EnFACE electrolyte and when additives are added to the bath. The additives used were Gleam A and B (Dow Chemical) which are used in printed circuit board manufacturing. The EnFACE electrolyte consisted of a $0.1 \mathrm{M} \mathrm{CuSO}_{4}$ solution without addition of acid. Additive levels of $17 \%, 33 \%, 50 \%, 100 \%$ and $200 \%$ of that recommended by the supplier were added to the solution. In addition, a solution of $0.63 \mathrm{M} \mathrm{CuSO}_{4}$ with $2.04 \mathrm{M}$ $\mathrm{H}_{2} \mathrm{SO}_{4}$ with additives as per supplier recommendations was also used in plating experiments.

Copper films of 25 um have been plated on polished steel coupons tests in a beaker without agitation. Deposits were plated from different electrolytes and subjected to ductility and resistivity tests. Deposit morphology was examined by scanning electron microscopy and electron back scatter diffraction. Yield strength and sheet resistance were measured to compare deposit properties against those recommended by Institute of 
Interconnecting and Packaging Electronic Circuits. Deposit properties are interpreted in terms of additive concentration in the bath. The effectiveness of using low concentrations of metal ions and additives on the influence deposit properties has been assessed.

\subsection{Experimental}

\subsection{Apparatus}

Electrodeposition experiments were carried out using a traditional two-electrode plating set-up. The working electrode was a dog-bone shaped stainless steel coupon with an area of $31.92 \mathrm{~cm}^{2}$. The counter electrode was a copper rod with an exposed area of 58.1 $\mathrm{cm}^{2}$. Plating was done in a 2-litre cell using the appropriate plating solution, and the current source was a Thurlby Thundar PL-310 power unit.

Morphological analysis (SEM and EBSD) was done using the JEOL JSM-5300LV. Resistivity of the plated films were measured using the Signatone Pro4 (four point probe) system in the Electronics and Electrical Engineering department Newcastle University UK. Mechanical properties were characterized using a Tinius Olsen H50KS with Horizon software for data recording. All tensile tests followed the ASTM E-345 [20], a standard for determining tensile properties of metallic films. Morphological and mechanical characterization were conducted in the Advanced Chemical and Materials Analysis (ACMA) laboratory, Newcastle University.

\subsection{Chemicals and Electrolytes}

Steel coupons (308 stainless) were manufactured to the specifications of IPC-TM-650 (IPC-TM stands for The Institute for Interconnecting and Packaging Electronic Circuits Testing Methods) standard. Technical grade $\mathrm{CuSO}_{4}$ and $\mathrm{H}_{2} \mathrm{SO}_{4}$ (Sigma-Aldrich) were used to prepare the plating electrolyte. The additives used were commercially available Copper Gleam series (Rohm Haas). Copper Gleam HS - 200 A served as the accelerator (SPS), while Copper Gleam B was the inhibitor (PEG). The $\mathrm{Cl}^{-}$ions were sourced from concentrated $\mathrm{HCl}$ (37\%, Sigma Aldrich). Chemicals for pre-treatment of the coupons include concentrated 
$\mathrm{HNO}_{3}$ and ethanol (Sigma Aldrich). The PRP200 photoresist (Electrolube) was used to insulate the backside of the coupons. Table 1 lists the composition of the different plating baths used for copper deposition.

\subsection{Procedure}

Prior to actual plating, the stainless steel coupons were cleaned with concentrated $\mathrm{HNO}_{3}$, and then rinsed with water for 1 minute. The coupons were mechanically polished using silicon carbide sheets, starting at grit \#220 and progressing to grit \#4000. One side of the coupon was coated with the photoresist, and left to dry. The exposed side of the coupon was swabbed with ethanol for 30 seconds and again allowed to dry.

Electrodeposition was carried out in direct current (DC) mode. The counter and working electrode was set-up in the plating cell containing different electrolytes. Table 2 shows the plating parameters used for the different experiments. These parameters were derived from polarization experiments that yielded limiting current regarding each bath type. Since the deposits become rougher as they approach the limiting current [21], the current was set at a fraction of this value to ensure that dendritic copper was not plated. The total plating time was calculated to obtain a copper film with thickness of $25 \mathrm{um}$.

After the allotted deposition time was reached, the coupons were removed from the solution and washed with deionized water for 1 minute. The surface was dried using a lint free cloth and left to dry in air. The plated copper films were then carefully peeled off from the stainless steel substrate, and were prepared for subsequent characterization. Each experiment was repeated three times to check for reproducibility.

For SEM and EBSD analysis, a $2 \times 2 \mathrm{~cm}^{2}$ area was cut out from the central portion of the copper coupon. For mechanical and resistivity testing, the whole coupon was used. Necessary care was taken to prevent damage on the coupons, particularly during handling and specimen mounting in the UTM that would compromise the quality of results of the mechanical tests. The values reported in this manuscript are the average of measurements from three different films. 


\subsection{Results and Discussion}

\subsection{Morphology and Grain Size Measurements}

Figure 1 shows the SEM images (planar view) of the products of the EnFACE bath with different additive concentration and the standard bath. It can be observed that as the amount of additive increased, the surface roughness of the deposit from the EnFACE bath noticeably decreased. In fact, the product of the bath with $100 \%$ and $200 \%$ additive concentrations appeared the smoothest and most compact among the lot. On the other hand, in terms of appearance, the deposit from the standard copper bath is similar to that of the E-33 and E-50 EnFACE bath, which showed that even at low concentrations the influence of additives is substantial.

The observed reduction in surface roughness may indicate the occurrence of a finegrained structure in the deposit. However, attempts to quantify the grain size of the copper films proved difficult since the grain structures were not easily discernible, even when viewed at high magnifications. Therefore, it became necessary to use another imaging technique that allowed accurate visualization of grain morphology. Electron back-scatter diffraction (EBSD) was chosen because the technique allows grain size and grain orientation analysis without the need to alter the surface condition of the metal.

Figure 2 shows the corresponding EBSD maps for the products of the EnFACE bath with different levels of additive concentration, and of the standard copper bath. The EBSD images revealed the grain structure, which were predominantly equiaxed for the electrolyte without additives, and becomes smaller as additive concentration is increased. The EBSD data allowed measurement of the grain size of deposits.

The rightmost column in Table 2 gives a summary of the calculated grain size of deposits measured using the EBSD image analyzing software TANGO (HKL Technology A/S, 2001). The grain structure map produced in EBSD was processed by performing noise reduction and wild spikes extrapolation. The band contrast was adjusted to clearly see the grains. The grain size parameter used is the major and minor axis of the fitted ellipse and the software automatically measures the grain size based on the delineation of all of the grain boundaries. 
Similar to the conclusions made from SEM analysis, the EBSD results indicated that additives created a finer grain structure in the deposit, and that the decrease in grain size was proportional to the concentration of additives used. The appearance of small grains inside the larger ones was further analyzed, and these small grains were identified as subgrains brought about by recrystallization. Dynamic recrystallization or self-annealing is a recognized phenomenon that exclusively occurs in copper plated from additive-containing electrolytes [22].

The SEM and EBSD results validate the grain-refining action of additives on the copper deposits. While numerous studies have reported similar observations in conventional copper baths $[23,24,25]$, these observations may be the first report on the effect of additives used for super-filling on the products of the EnFACE bath. It is also observed that the grain refining effect of additives on the EnFACE bath is more pronounced than in the standard bath. This was seen with the finer grain size obtained in the EnFACE copper compared to the standard copper at the same additive concentration.

Grain refinement is one of the most important morphological and structural effects of additives [24]. It is known that additives affect the mechanisms of nucleation and growth during plating [26]. For example, brighteners enhance nucleation rates, while leveling agents inhibit dendritic growth. Both these actions can contribute to creating the finegrained structure seen in the deposits. The effect could even be synergistic when different types of additives are present in the electrolyte. Since, grain refinement would affect the mechanical and electrical properties, these properties were measured and are reported below.

\subsection{Mechanical and Resistance Measurements}

Figure 3 shows the resistivity measurements for different additive concentration using EnFACE electrolyte. Clearly, the progressive addition of additives created a more resistive copper deposit. Furthermore, the resistivity of some of the EnFACE copper is similar in value to copper deposited from a standard electrolyte; i.e., the resistivity is 2.27 $\mu o h m-\mathrm{cm}$ when copper is plated from a standard bath, and 2.30 and $2.31 \mu \mathrm{ohm}-\mathrm{cm}$ when deposited from E-33 and E-50, respectively. 
The increase in the resistivity of the copper film is explained by the significant reduction of grain size brought about by additive use. Morphological analysis presented earlier has already confirmed a change in grain size. Grain boundaries, together with other defects, act as electron scattering centers and reduce the effective displacement of the free electrons during electronic conduction [27]. Thus, the increase in grain boundary area during grain refinement caused the increase resistivity of the deposited film.

Figure 4 shows the plot of mechanical properties; namely, $0.2 \%$ offset yield strength (YS), ultimate tensile strength (UTS), and the ductility of the electrodeposited copper films, as a function of additive concentration. The results reveal the strong effect of additive concentration on mechanical properties. Both YS and TS increased while ductility decreased with increasing additive concentrations. The percent increase in YS and TS, and the \% decrease in ductility are almost similar; a $\sim 40 \%$ change in value from the lowest to the highest additive concentration.

Table 3 summarises the mechanical properties of copper plated from a standard bath. The Institute for Interconnecting and Packaging Electronic Circuits advises that copper Using these values, it can be seen that plated films from EnFACE electrolytes are closer to the specification of the Institution than those obtained from the standard electrolyte. It is envisaged that by optimising bath and plating conditions, the specifications for interconnections and packaging can be achieved.

The observed trends in the plated copper are consistent with the well-known mechanical behavior of metals. Typically, an increase in the metal's strength will be accompanied by a loss in ductility. The results also indicate a clear improvement in the mechanical strength of the plated copper when additives are used with the bath. To explain how additive concentration affects mechanical properties, one needs to consider the plated metal's inherent microstructural features. Important microstructural features include dislocation, grain boundaries and voids [25].

It is reasonable to assume that the observed grain size refinement directly caused the changes in the metal's yield strength and ductility; a statement consistent with published work [29, 30,31]. Classical theories on slip and plastic yielding explain how grain 
boundaries can serve as dislocation barriers, thereby lowering dislocation mobility and preventing easy plastic deformation to occur. Consequently, such an action increases YS and lowers ductility. Tensile strength, on the other hand, is strongly affected by the amount of voids, and an inverse relation exists between the two.

\subsection{Optimum Additive Concentration}

By inspecting the properties of the copper plated from EnFACE electrolytes containing different concentration of additives, it was found that at an additive concentration of $50 \%$, the plated copper has properties close to the specifications stated by IPC. Though the properties of the E-50 electrolyte is slightly different from the values specified, they are closer than those obtained from a standard electrolyte. It can be envisaged that further improvements in deposit properties could be obtained by optimising plating conditions.

Notably, the EnFACE electrolyte has a low metal ion concentration, which can limit plating rates (c.f. Table 2). In fact, the plating rate of the standard electrolyte is nearly four times higher than the best EnFACE electrolyte (E-50). This means that the rate of plating needs to be increased by improving agitation. In many industries, such as circuit board manufacturing, plating rates of 1.5-2.0 ASD $\left(15-20 \mathrm{~mA} / \mathrm{cm}^{2}\right)$ are advised. Since all of the EnFACE electrolytes exceed this plating rate, it should not affect plating rates in an industrial environment. On the other hand, by operating baths which have low metal and additive concentration, savings and sustainability can be achieved.

\subsection{Conclusions}

Copper was successfully plated from the additive containing EnFACE bath, and its properties were characterized and compared to that achieved using a standard electrolyte. Stainless steel coupons were plated with 25 um copper films using electrolytes of different additive concentrations. Additives caused the refinement of the grain structure of deposits, and the decrease in grain size was proportional to the concentration of additive used. This grain refinement consequently increased resistivity, yield and tensile strength, and reduced 
235 the ductility of plated copper. The EnFACE bath required a lower amount of additive to 236 obtain a product that has comparable properties to that obtained from a standard 237 electrolyte. The optimum additive concentration appears to be about $50 \%$ lower than the 238 industry recommended dosage.

239

240 Acknowledgement

241 This work was supported by MESMOPROC (www.mesmoproc.eu) funded by the EACl Grant 242 MP1307.

243 *This work commenced in Newcastle University. Both Newcastle authors have changed 244 their affiliation to Strathclyde University.

245

246

247 
249 [1] P.C. Andricacos, C. Uzoh, J.C. Dukovic, J. Horkans and H. Deligiani, IBM J. Res. Dev. (1998) $250 \quad 42,567$.

251 [2] S. Franssila, $2^{\text {nd }}$ Edition, John Wiley \& Sons Ltd (2010), West Sussex, United Kingdom.

252 [3] A. Brenner, Academic Press (1962), New York.

253 [4] S.S. Kruglikov, N.T. Kudriavtsev, G.F. Vorobiova and A.Ya. Antonov, Electrochimica Acta 254 (1965), 10, 253-261.

255 [5] G. Fabricus and G. Sundholm, Journal of Applied Electrochemistry (1985) 15, $797-801$.

256 [6] T.C. Franklin, Surface and Coating Technology (1987), 30, 415 - 428.

257 [7] L. Oniciu and L. Muresan, Journal of Applied Electrochemistry (1991), 565-574.

258 [8] E. Michailova, I. Vitanova, D. Stoychev, and A. Milchev, Electrochimica Acta (1993), 259 38(16), 2455-2458.

260 [9] J.J. Kelly, C. Tian and A.C. West, Journal of Electrochemical Society (1998), 146 (7) 2540 2612545.

262 [10] S. Nouraei and S. Roy, Electrochimica Acta (2009), 54, 2444-2449.

263 [11] Roy, S. 2007. Journal of Physics D: Applied Physics. Vol. 40(22), R413-R426.

264 [12] Q. Wu, T.A. Green and S. Roy, Electrochemistry Communications (2011), 13, 1229-1232.

265 [13] S. Coleman, and S. Roy, Chemical Engineering Science (2014), 113, 35-44.

266 [14] S. Coleman and S. Roy, Journal of Applied Electrochemistry (2015), 45 (8), 889-898.

267 [15] I. Schönenberger and S. Roy, Electrochimica Acta (2005), 51, 809-19.

268 [16] U. Landau, Plenum Press (1982), New York.

269 [17] L.N. Schoenberg, J. Electrochem. Soc. (1971), 118(70), 1571-1576.

270 [18] M. Paunovic and R. Arndt, J. Electrochem. Soc. (1983), 130, 794-799.

271 [19] T.P. Moffat, D. Wheeler and D. Josell, The Electrochemical Society Interface, Winter 2722004.

273 [20] ASTM E-345 Standard Test Methods of Tension Testing of Metallic Foil.

274 [21] T.P. Moffat, D. Wheeler, C. Witt and D. Josell, Electrochem. and Solid-State Lett. (2002), 275 5, C110-C112. 
276 [22] C. Cabral Jr., C. Andricacos, L. Gignac, IC. Noyan, K.P. Rodbel, T.M. Shaw, R. Rosenberg,

277 and JME Harper, Abstracts of the Advanced Metallization Conference (AMC), October 6-8,

278 1998, Colorado Springs, Colorado.

279 [23] M. Paunovic and R. Arndt, Surface Preparation and Finishes for Metals. J. Electrochem.

280 Soc. (1983), 130, 794-799.

281 [24] L. Oniciu and L. Muresan, Journal of Applied Electrochemistry (1991), 21, 565-574.

282 [25] D. Dini and D. Snyder, Modern Electroplating: $5^{\text {th }}$ Edition" Edited by Mordechay 283 Schlesinger, Milan Paunovic, John Wiley and Sons (2010), NY.

284 [26] M. Tan, C. Guymon, D. Wheeler, and J. Harb, J. Electrochem. Soc. (2007) 154(2), D78-

285 D81.

286 [27] W. Callister W, Materials Science and Engineering: An Introduction. $7^{\text {th }}$ edition,

287 Hoboken, NJ : John Wiley \& Sons (2007).

288 [28] IPC-TM-650 test methods manual. Number 2.4.18. The Institute for Interconnecting and 289 Packaging Electronic Circuits, 2215 Sanders Road, Northbrook, IL.

290 [29] E.M. Hofer and H.E. Hintermann, Journal of the Electrochemical Society (1965), 112, 291 167-173.

292 [30] E. Michailova, I. Vitanova, D. Stoychev and A. Milchev, Electrochimica Acta (1993), 293 38(16), 2455-2458.

294 [31] E. Rusli, F. Xue, T. Drews, P. Vereecken, P. Andricacos, H. Deligianni, R. Braatz and R. 295 Alkire, Journal of the Electrochemical Society (20070, 154 (11) D584 - D597.

296

297

298

299

300

301

302 
Figure 1: SEM images of copper deposits from EnFACE bath with different additive concentration: a) E-17 with $17 \%$ additive concentration, b) E-33 with $33 \%$ additive concentration, c) E-50 with $50 \%$ additive concentration, d) E-100 with $100 \%$ additive concentration and e) E-200 with $200 \%$ additive concentration, and f) S - standard bath. These percentages are relative to the industry recommended additive concentration of 10 $\mathrm{ml} / \mathrm{L}$ Copper Gleam B, $0.5 \mathrm{ml} / \mathrm{L}$ Copper Gleam A, and 70 ppm Cl .

Figure 2: EBSD images of copper deposits from EnFACE bath with different additive concentration: a) E-17 with $17 \%$ additive concentration, b) E-33 with $33 \%$ additive concentration, c) E-50 with $50 \%$ additive concentration, d) E-100 with $100 \%$ additive concentration and e) E-200 with $200 \%$ additive concentration, and f) S - standard bath. These percentages are relative to the industry recommended additive concentration of 10 $\mathrm{ml} / \mathrm{L}$ Copper Gleam B, $0.5 \mathrm{ml} / \mathrm{L}$ Copper Gleam A, and 70 ppm Cl${ }^{-}$. The calibration bar is for 2 um length. The different colors in the EBSD map represent different crystals planes as described by the $\mathrm{g}$ ) inverse pole legend.

Figure 3: Resistivity measurements of electrodeposited copper films using EnFACE electrolyte with varying additive concentrations.

Figure 4: The a) yield strength, b) tensile strength and ductility of plated copper films using EnFACE electrolyte with varying additive concentrations. 
Table 1: Bath composition and nomenclature.

\begin{tabular}{|c|c|c|c|c|c|c|}
\hline Designation & Setting description & $\begin{array}{c}\mathrm{Cu}_{2} \mathrm{SO}_{4} \\
\mathrm{M}\end{array}$ & $\begin{array}{c}\mathrm{H}_{2} \mathrm{SO}_{4} \\
\mathrm{M}\end{array}$ & $\begin{array}{c}\text { Gleam B } \\
\mathrm{ml} / \mathrm{L}\end{array}$ & $\begin{array}{c}\text { Gleam A } \\
\mathrm{ml} / \mathrm{L}\end{array}$ & $\begin{array}{l}\mathrm{HCl} \\
\mathrm{ppm}\end{array}$ \\
\hline$S$ & Standard bath & 0.63 & 2.04 & 10 & 0.5 & 70 \\
\hline S-0 & $\begin{array}{c}\text { Standard bath without } \\
\text { additives }\end{array}$ & 0.63 & 2.04 & $x$ & $x$ & $x$ \\
\hline $\mathrm{E}-\mathrm{O}$ & $\begin{array}{l}\text { EnFACE bath without } \\
\text { additives }\end{array}$ & 0.1 & $x$ & $x$ & $x$ & $x$ \\
\hline$E-17$ & $\begin{array}{l}17 \% \text { of the recommended } \\
\text { additive concentration }\end{array}$ & 0.1 & $x$ & 1.7 & 0.08 & 12 \\
\hline$E-33$ & $\begin{array}{l}33 \% \text { of the recommended } \\
\text { additive concentration }\end{array}$ & 0.1 & $x$ & 3.3 & 0.17 & 23 \\
\hline$E-50$ & $\begin{array}{l}50 \% \text { of the recommended } \\
\text { additive concentration }\end{array}$ & 0.1 & $x$ & 5.0 & 0.25 & 35 \\
\hline $\mathrm{E}-100$ & $\begin{array}{l}\text { Recommended additive } \\
\text { concentration }\end{array}$ & 0.1 & $x$ & 10.0 & 0.50 & 70 \\
\hline$E-200$ & $\begin{array}{l}\text { High concentration } \\
\text { (double of the } \\
\text { recommended additive) }\end{array}$ & 0.1 & $x$ & 20.0 & 1.0 & 140 \\
\hline
\end{tabular}

"S" stands for "standard" electrolytes based on supplier recommendation and " $E$ " stands for "Enface" baths. The number following the " $S$ " and " $E$ " stand for the percent of additive concentration added to the electrolyte 


\begin{tabular}{|c|c|c|c|}
\hline Electrolyte & $\begin{array}{c}\text { Plating current } \\
\mathrm{mA} \\
\text { (40\% from ILM) }\end{array}$ & $\begin{array}{c}\text { Plating time } \\
\text { minutes }\end{array}$ & $\begin{array}{c}\text { Grain size } \\
\text { From EBSD } \\
(\mathrm{nm})\end{array}$ \\
\hline S & 245 & 146 & 431 \\
\hline S-0 & 255 & 152 & 11524 \\
\hline E-0 & 68 & 615 & 9016 \\
\hline E-17 & 68 & 623 & 758 \\
\hline E-33 & 63 & 623 & 523 \\
\hline E-50 & 58 & 669 & 466 \\
\hline E-100 & 54 & 705 & 407 \\
\hline E-200 & 53 & 708 & 400 \\
\hline
\end{tabular}

352

353

354

355

356

357 
Table 3: Mechanical properties of copper plated from S, S-0 and E-50 bath.

359

\begin{tabular}{|c|c|c|c|}
\hline Bath & YS $_{0.2 \%}, \mathrm{MPa}$ & $\mathrm{TS}, \mathrm{MPa}$ & Ductility, \% \\
\hline $\mathrm{S}$ & 219 & 256 & 1.69 \\
\hline $\mathrm{S}-0$ & 136 & 145 & 2.77 \\
\hline E-50 & 170 & 213 & 2.17 \\
\hline
\end{tabular}

360

361

362

363

364

365

366

367

368

369

370

371

372 


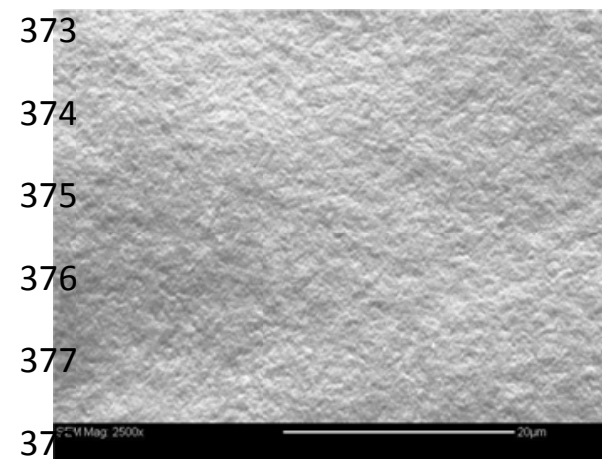

379

a) $\mathrm{E}-17$

380

381

382

383

384

38

386

d) $E-100$

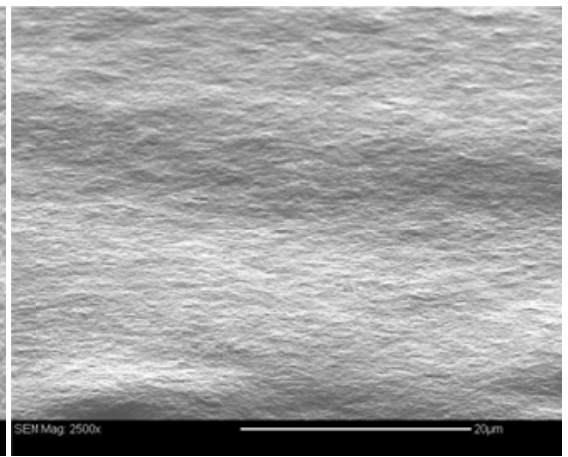

b) $E-33$

c) $\mathrm{E}-50$

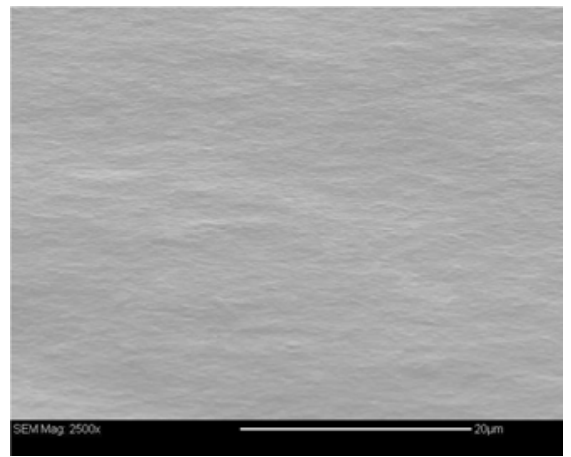

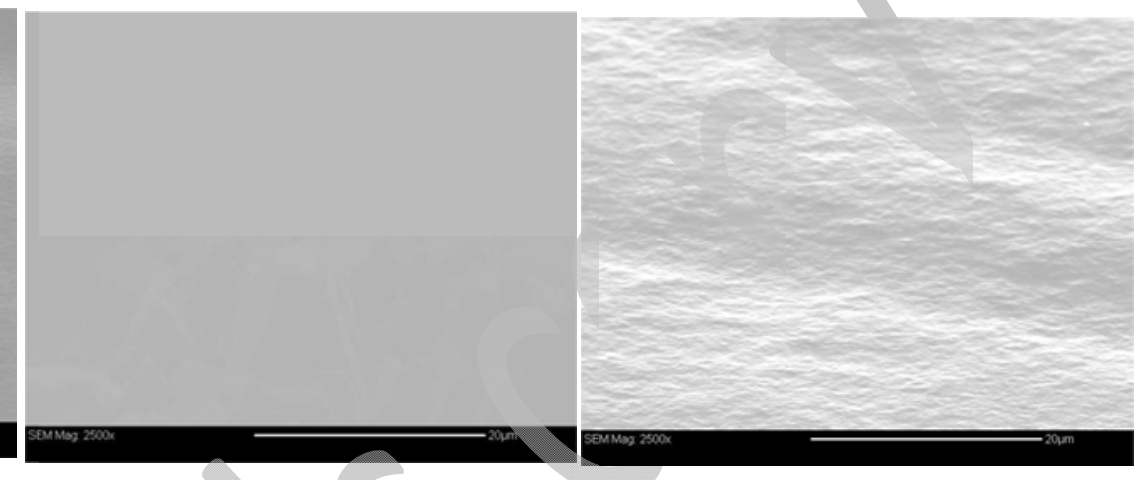

e) $E-200$

f) $S$

387

388 Figure 1: SEM images of copper deposits from EnFACE bath with different additive 389 concentration: a) E-17 with $17 \%$ additive concentration, b) E-33 with $33 \%$ additive 390 concentration, c) E-50 with 50\% additive concentration, d) E-100 with $100 \%$ additive 391 concentration and e) E-200 with 200\% additive concentration, and f) S - standard bath. 392 These percentages are relative to the industry recommended additive concentration of 10 $393 \mathrm{ml} / \mathrm{L}$ Copper Gleam B, $0.5 \mathrm{ml} / \mathrm{L}$ Copper Gleam A, and 70 ppm Cl${ }^{-}$. 
402

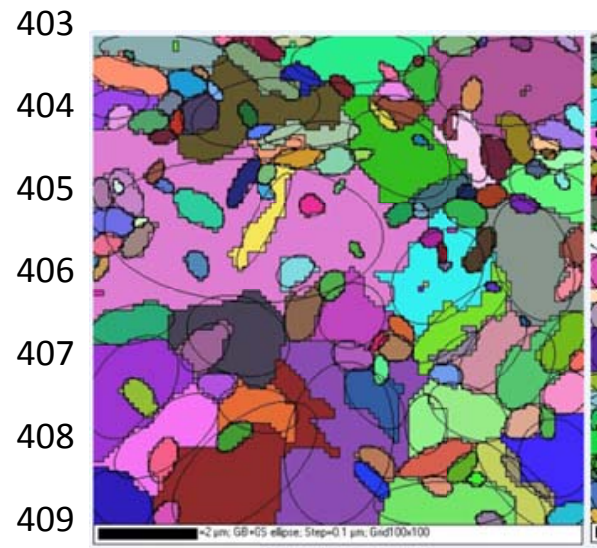

410

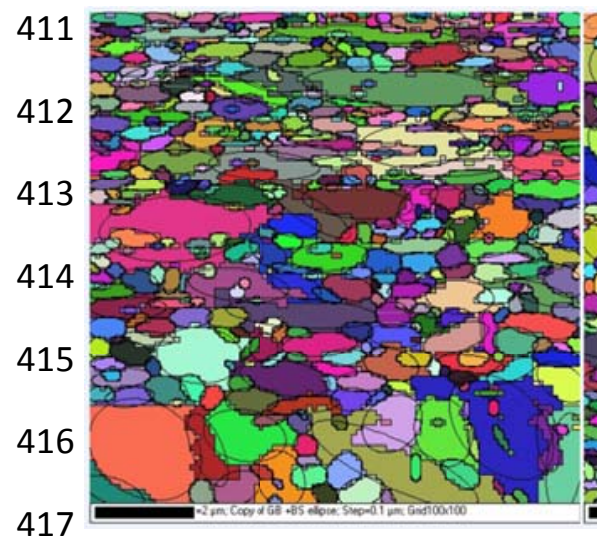

418

419

420

421

422

423

424

425

426

427

428

429

430

431

d) $E-100$

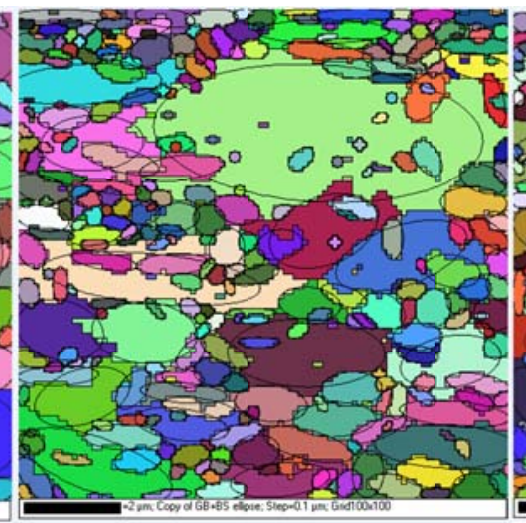

b) $E-33$

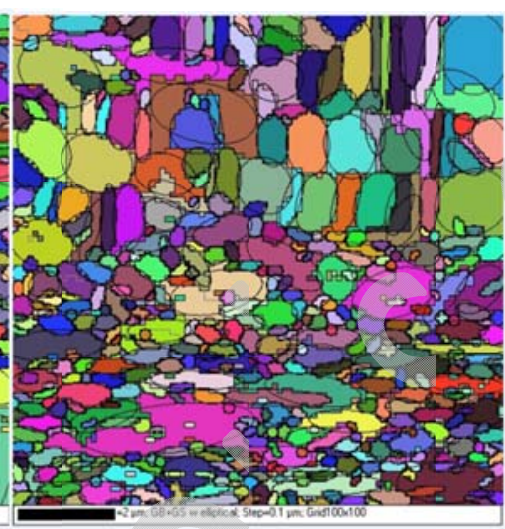

e) $E-200$



c) $E-50$



f) $S$



g) Inverse pole legend

Figure 2: EBSD images of copper deposits from EnFACE bath with different additive concentration: a) E-17 with $17 \%$ additive concentration, b) E-33 with $33 \%$ additive concentration, c) E-50 with $50 \%$ additive concentration, d) E-100 with $100 \%$ additive concentration and e) E-200 with $200 \%$ additive concentration, and f) S - standard bath. These percentages are relative to the industry recommended additive concentration of 10 $\mathrm{ml} / \mathrm{L}$ Copper Gleam B, $0.5 \mathrm{ml} / \mathrm{L}$ Copper Gleam A, and $70 \mathrm{ppm} \mathrm{Cl}$. The calibration bar represents a length of $2 \mathrm{um}$. The different colors in the EBSD map represent different crystals planes as described by the g) inverse pole legend. 


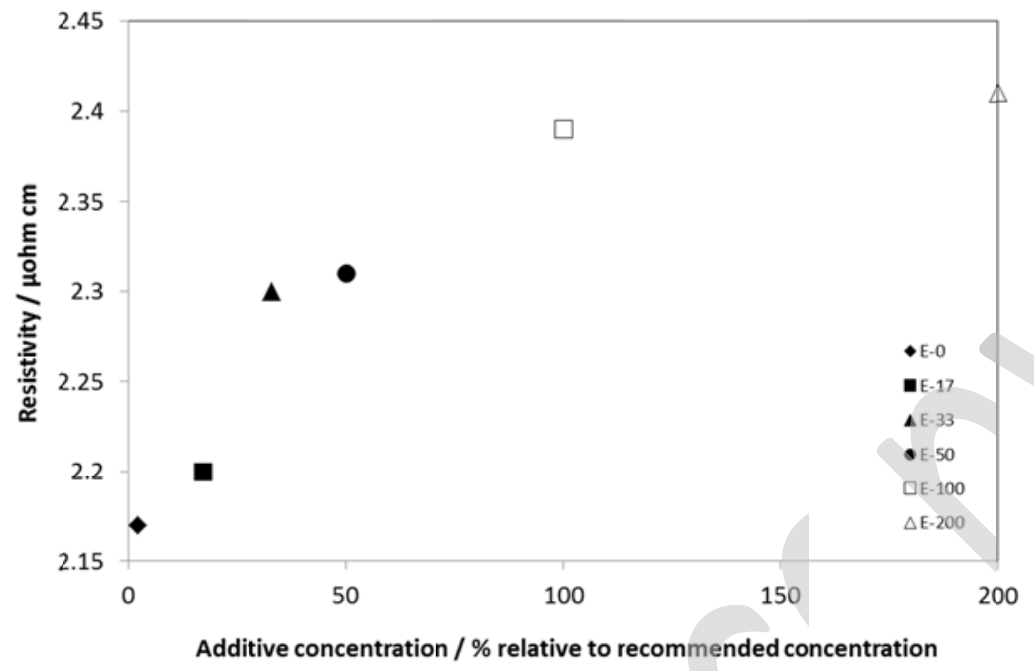

436

437 Figure 3: Resistivity measurements of electrodeposited copper films using EnFACE

438 electrolyte with varying additive concentrations.

439

440

441

442

443

444

445

446

447

448

449

450

451

452

453 


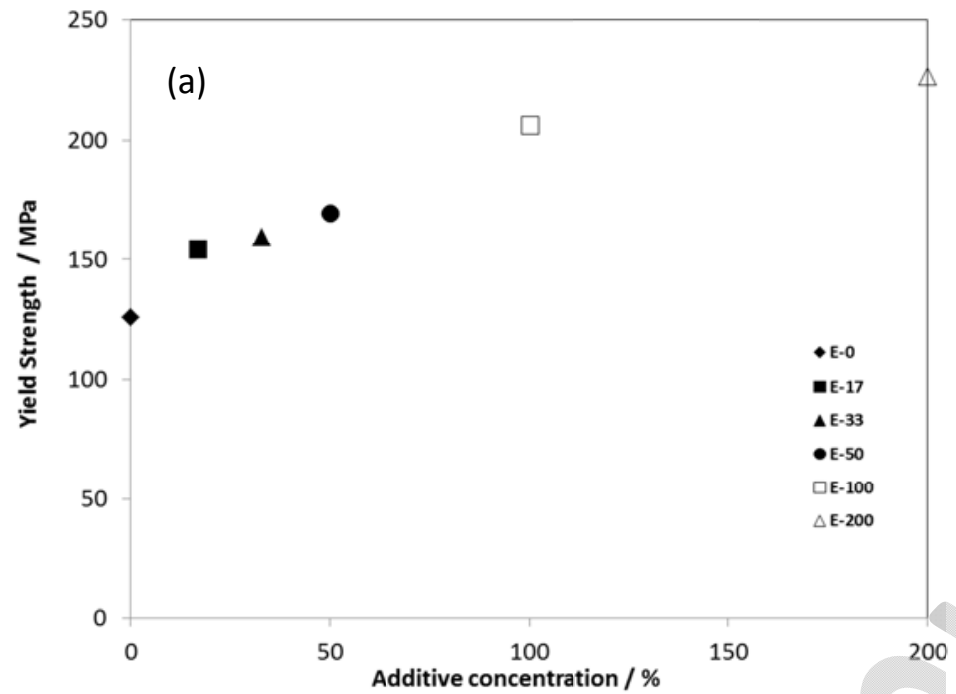

454

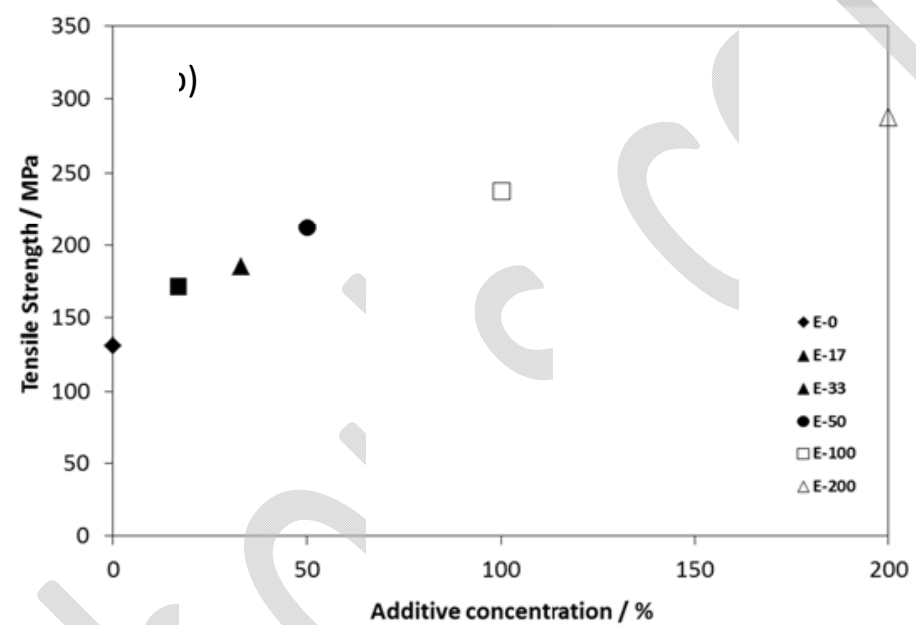

455

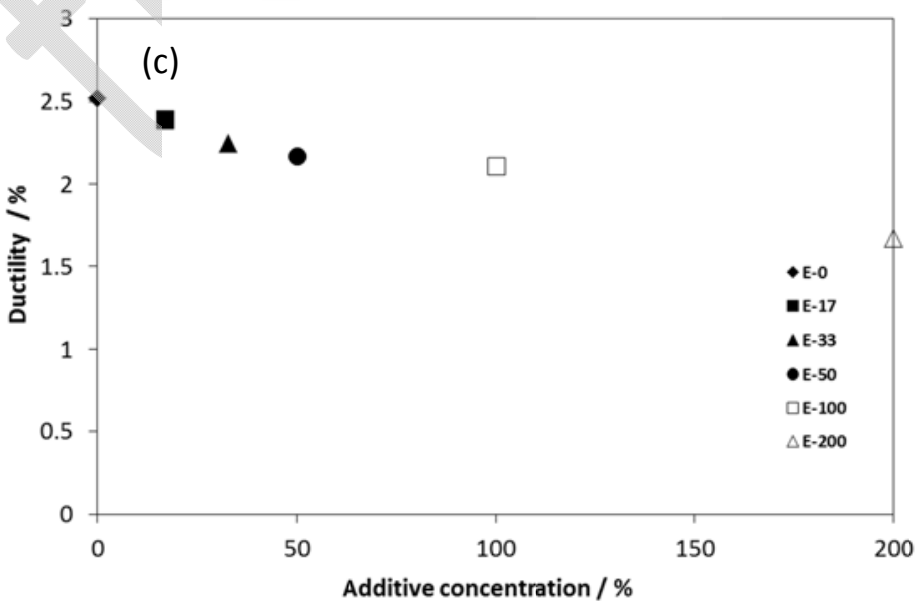

456

457 Figure 4: The a) yield strength, b) tensile strength and ductility of plated copper films

458 using EnFACE electrolyte with varying additive concentrations. 